\title{
Relapse to Heroin-Seeking in Rats under Opioid Maintenance: The Effects of Stress, Heroin Priming, and Withdrawal
}

\author{
Yavin Shaham, Heshmat Rajabi, and Jane Stewart \\ Center for Studies in Behavioral Neurobiology, Department of Psychology, Concordia University, Montreal, Quebec, \\ Canada $H 3 G 1 M 8$
}

It is widely believed that opioid withdrawal symptoms contribute to relapse to opioid use, but relapse is highly probable in experienced users even after prolonged abstinence and during opioid maintenance therapy. We have found using an animal model of relapse, the reinstatement procedure, that the two events that reliably reinstate heroin-seeking behavior are reexposure to heroin, and brief exposure to footshock stress. Contrary to expectation, opioid antagonist-induced withdrawal does not reinstate heroin-seeking. We now report on reinstatement of heroin-seeking in rats trained to self-administer heroin and subsequently exposed to a maintenance dose of heroin via minipump and allowed to self-administer saline. With the minipump in, naloxone-induced withdrawal did not reinstate drug-seeking, a priming injection of heroin was only mildly effective, and footshock was highly effective. Twenty-four hours after removal of the minipump (spontaneous withdrawal), ani- mals reinitiated heroin-seeking and, subsequently, both heroin and footshock reinstated heroin-seeking. In summary, brief exposure to stress reinstated heroin-seeking in both heroinmaintained and withdrawn animals. The heroin prime reliably reinstated drug-seeking only in the absence of the minipump; opioid "withdrawal," as such, did not reinstate drug-seeking behavior. Naloxone given to heroin-maintained animals induced withdrawal symptoms, caused a mild depression in the levels of dopamine and its metabolites in the nucleus accumbens septi (NAS), but did not reinstate drug-seeking. Reinstatement of heroin-seeking during spontaneous withdrawal was not accompanied by reductions in basal dopamine and its metabolites in NAS.

Key words: opioid self-administration; relapse; priming; stress; withdrawal; nucleus accumbens; dopamine
Theories of opioid self-administration posit a major role for withdrawal symptoms in the maintenance and relapse to drugtaking after periods of abstinence (Himmelsbach, 1943; Nichols et al., 1956; Solomon and Corbit, 1974). Users have the opportunity to learn that opioid drugs can alleviate the symptoms of withdrawal, and it makes sense that when such symptoms occur experienced users might seek out and take these drugs. It has been suggested, furthermore, that because opioid-like withdrawal symptoms can be evoked by drug-related stimuli through associative conditioning, these stimuli, by evoking withdrawal symptoms, can induce relapse even after long periods of abstinence (Wikler, 1973; Siegel, 1977; O'Brien et al., 1986).

Despite many years of research, however, a major role for the state of withdrawal in compulsive opioid use and relapse has not been established. It has been difficult to demonstrate in animals any motivational role for withdrawal states in opioid-taking (Stewart et al., 1984), and attempts to reinstate heroin-seeking behavior by precipitating withdrawal directly have met with failure (Shaham and Stewart, 1995b). Animals self-administering morphine or heroin have been shown to take more of the drug when given injections of an opioid antagonist, but the behavior of such ani-

Received Oct. 2, 1995; revised Nov. 27, 1995; accepted Dec. 11, 1995.

This research was supported by grants to J.S. from the Medical Research Council of Canada and from the Fonds pour la Formation de Chercheurs et l'Aide à la Recherche (Québec). Y.S. holds a Postdoctoral Fellowship from the Medical Research Council of Canada. We thank Jennifer Puddicombe and Demetra Rodaros for their expert technical assistance.

Correspondence should be addressed to Jane Stewart, Center for Studies in Behavioral Neurobiology, Department of Psychology, Concordia University, 1455 de Maisonneuve Boulevard, Montreal, Quebec, Canada H3G 1 M8.

Copyright (C) 1996 Society for Neuroscience $0270-6474 / 96 / 161957-07 \$ 05.00 / 0$ mals is similar to those given lower doses of morphine or heroin (for discussion of this issue, see Stewart and Eikelboom, 1987). Furthermore, attempts to demonstrate that previous pairings between exposure to the opioid drug and alleviation of withdrawal would actually increase drug-taking in a relapse phase have not been successful (Wikler and Pescor, 1967; Miller et al., 1979). Studies by Wikler and others (Thompson and Ostlund, 1965; Wikler and Pescor, 1967; Wikler et al., 1971; Sobrero and Bouton, 1989) have also failed to demonstrate that a conditioned state of withdrawal evoked by presentation of stimuli previously paired with opioid withdrawal can induce relapse to drug use (see also Stewart et al., 1984). Furthermore, in humans withdrawal symptoms evoked by exposure to drug-related cues are only modestly related to self-reports of craving (Childress et al., 1986; O'Brien et al., 1992).

Despite the lack of evidence for a positive relationship between the state of withdrawal and relapse, the opioid-withdrawal syndrome is receiving considerable attention as an important contributor to drug-seeking behavior in the drug-free state. The revival of this view (Koob et al., 1992) is attributable largely to recent observations made using microdialysis that opioid antagonists given to morphine-dependent rats precipitate withdrawal symptoms and decrease extracellular dopamine (DA) overflow in nucleus accumbens septi (NAS) (Pothos et al., 1991; Rossetti et al., 1992), whereas injections of opioid agonists increase DA overflow in this brain region (Di Chiara and Imperato, 1988). The reason this is considered significant is that increased DA activity in this region of the brain has been shown to be correlated with the positive-reinforcing effects of opioid drugs (Shippenberg et al., 1992; Devine et al., 1993; Devine and Wise, 1994). Furthermore, 


\section{Experimental Design}

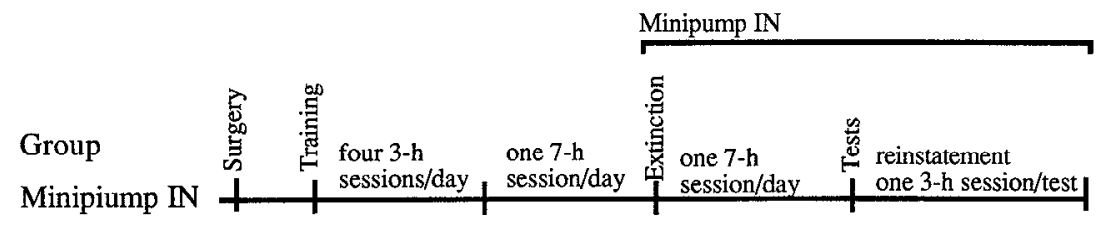

Figure 1. Diagram showing the sequence of treatments of the Minipump IN and the Minipump OUT groups in the study of reinstatement.

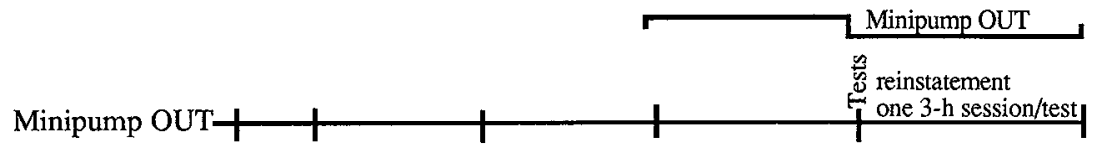

it has been shown that blockade of $D_{2}$ DA receptors in the NAS can elicit somatic withdrawal symptoms in morphine-dependent rats, whereas injections of $D_{2}$ DA receptor agonists into the NAS attenuate naloxone-precipitated withdrawal symptoms in these rats (Harris and Aston-Jones, 1994). Such studies suggest that the mesolimbic DA system may be involved in both opioid reinforcement and opioid withdrawal, but they do not address directly the question of the relationships among symptoms of opioid withdrawal, decreased levels of extracellular DA in the NAS, and relapse to drug use.

In previous studies, we have found two events to be highly effective in reinstating heroin-seeking, a priming injection of heroin itself, and brief exposure to footshock stress; however, naltrexone-precipitated withdrawal was ineffective. The fact that both the priming injection of heroin and footshock led to increased levels of DA in NAS, whereas injection of naltrexone 40 min after exposure to morphine (precipitated withdrawal) reversed morphine-induced elevations in DA levels, brings into question a direct link between depressed DA levels and relapse (Shaham and Stewart, 1995a,b).

In the present study, we approached the question of the conditions for reinstatement of heroin-seeking and, in particular, the role of opioid withdrawal by studying the behavior of experienced heroin using animals kept on maintenance levels of heroin via minipumps. In this way we have been able to compare reinstatement of heroin-seeking behavior in the presence of an opioid agonist in the body with reinstatement of drug-seeking in its abscnce.

\section{MATERIALS AND METHODS}

\section{Experiment 1: reinstatement}

Subjects. Twenty-four male Long-Evans rats (300-400 gm; Charles River, Montreal, Canada) were transferred from the animal housing facility to operant chambers 1 week after surgery. The animals lived in the operant chambers for $24 \mathrm{hr} / \mathrm{d}$ and were maintained on a reversed light/dark cycle (lights on 1 U P.M. to 10 A.M.) throughout the experiment. Food and water were available except during the $3 \mathrm{hr}$ tests for reinstatement described below. The catheters were flushed daily with $0.2 \mathrm{ml}$ of a saline-heparin solution ( 30 $\mathrm{U} / \mathrm{ml}$ heparin, ICN Biochemical, Cleveland, OH).

Surgery. The animals were surgically implanted with intravenous SII.ASTIC catheters [Dow Corning, Midland, MI; inner diameter (i.d.) 0.02 in., outer diameter (o.d.) 0.037 in.] in the right jugular vein under sodium pentobarbital anesthesia $(65 \mathrm{mg} / \mathrm{kg}$, i.p.; MTC Pharmaceutical, Cambridge, Ontario, Canada). Atropine sulfate $(0.6 \mathrm{mg} / \mathrm{ml}, 0.3 \mathrm{ml} / \mathrm{animal}$; MTC Pharmaceutical) and Ayercillin $(300,000 \mathrm{IU}, 0.2 \mathrm{ml} / \mathrm{animal}$; WyethAyerst, Montreal, Canada) were given at the time of surgery. The catheler was secured to the vein with a silk suture and passed subculaneously to the top of the skull where it exited into a connector (a modified 22-gauge cannula; Plastic One, Roanoke, VA) mounted to the skull with jeweler's screws and dental cement.

Apparatus. The operant chambers used had two levers located $9 \mathrm{~cm}$ above the floor, but only one lever (an "active," retractable lever; Med Associates, Lafayette, IN) activated the infusion pump (Razel Scientific Instruments, Stamford, CT). Presses on the other lever ("dummy," stationary lever) were recorded, but did not activate the infusion pump. A given drug dose was infused at a volume of $0.13 \mathrm{ml}$ during a $20 \mathrm{sec}$ period. During the infusion, a light located above the active lever was lit for 20 sec. Bar presses during those $20 \mathrm{sec}$ were counted, but did not lead to further infusions. The grid floors of the chambers were connected to electric shock generators.

Drugs. Diacetylmorphine $\mathrm{HCl}$ (heroin) was obtained from Health and Welfare office of Canada. Naloxone $\mathrm{HCl}$ was obtained from DuPont NEN (Wilmington, DE). Drugs were dissolved in physiological saline.

Procedure. Figure 1 outlines the sequence of treatments given to the two groups studied. Animals were trained to self-administer heroin (100 $\mu \mathrm{g} / \mathrm{kg}$ per infusion) over $4-5 \mathrm{~d}$, during which each lever press was reinforced. Each day was divided into four $3 \mathrm{hr}$ sessions (2 during the dark and 2 during the light) separated by $3 \mathrm{hr}$. The first session of each day started at the beginning of the dark period, 10 A.M. Throughout the experiment, each session began by the introduction of the retractable lever into the cage and the illumination of the white light above the lever for $30 \mathrm{sec}$. A red house-light was turned on for the entire session. After training rats were allowed to self-administer heroin for $6-7 \mathrm{~d}$, one $7 \mathrm{hr}$ session/d (10 A.M. to 5 P.M.). These 7 hr daily sessions were instituted to allow the animals to associate the administration of heroin with the alleviation opioid withdrawal. Opioid withdrawal symptoms are maximal 12-24 hr after last exposure to the drug (Wikler and Pescor, 1967). All animals were then implanted subcutaneously with osmotic minipumps (model 2002, Alza Corporation, Palo Alto, CA) under light methoxyflurane (Metofane, Jannsen Pharmaceutical, Mississauga, Ontario, Canada) anesthesia. The minipumps delivered heroin at a dose of $3 \mathrm{mg} / \mathrm{kg}$ per 24 $\mathrm{hr}$, a dose similar to that self-administered during the $7 \mathrm{hr}$ daily training sessions $(3.1 \pm 0.6 \mathrm{mg} / \mathrm{kg})$. Extinction sessions were then conducted for $5 \mathrm{~d}(7 \mathrm{hr}$ session/d) during which presses on the active lever resultcd in saline infusions. Before each session, the animals were given a subcutaneous injection of saline to habituate them to the injection procedure.

lests for reinstatement of heroin-seeking behavior followed. The duration of test sessions was $3 \mathrm{hr}$ (10 A.M. to 1 P.M.). Rats were initially tested daily for reinstatement after a priming injection of subcutaneous saline (baseline condition). Saline was injected within $10 \mathrm{~min}$ before the start of the test session. Tests with saline prime continued for up to 4 daily sessions until all rats reached a criterion for extinction of $<20$ lever presses on the active lever. Animals were then assigned to one of two groups, a Minipump IN group ( $n=13)$ and a Minipump OUT group ( $n$ $=11$ ). Those in Minipump IN group were tested for reinstatement after exposure, in a counterbalanced order, to injection of the opioid antagonist naloxone $(0.1 \mathrm{mg} / \mathrm{kg}$, s.c.; precipitated withdrawal), priming injection of heroin, and $10 \mathrm{~min}$ of intermittent footshock [0.5 mA; $0.5 \mathrm{sec}$ on, mean off period of $40 \mathrm{sec}$ (range 10-70 sec)] just before the test session. Those in group Minipump OUT had the minipumps removed immediately after the last baseline test with a saline prime and were tested for reinstatement $24 \mathrm{hr}$ later (spontaneous withdrawal). Subsequently, they were tested in a countcrbalanced order aftcr a priming injection of heroin and footshock. Reinstatement tests were conducted once a day at the beginning of the dark cycle. Saline, heroin, or naloxone was injected within $10 \mathrm{~min}$ before the start of the test session. Footshock was administered for 10 min just before the start of the session. Tests for reinstatement were conducted 
under extinction conditions (i.e., presses on the active lever resulted in saline infusions).

A pilot study with the osmotic minipumps $(3 \mathrm{mg} / \mathrm{kg} / \mathrm{d}$ of heroin) revealed that naloxone doses of 0.1 and $1.0 \mathrm{mg} / \mathrm{kg}$, but not of $0.01 \mathrm{mg} / \mathrm{kg}$, reliably precipitate opioid-withdrawal symptoms. The precipitated withdrawal condition was quantified by recording for 30 min episodes of teeth chattering and wet-dog shakes (Blasig et al., 1973). The priming dose of $0.25 \mathrm{mg} / \mathrm{kg}$ heroin, s.c., was used because it has been found to be the most effective dose for reinstatement of heroin-seeking in drug-free rats in a previous experiment (Shaham and Stewart, 1995a). This dose had a similar, although somewhat weaker, effect on reinstatement than $10 \mathrm{~min}$ exposure to intermittent footshock.

\section{Experiment 2: microdialysis}

Subjects and surgery. Forty additional male Long-Evans rats (300-350 gm) were implanted with 20-gauge stainless-steel guide cannulae (Plastics One) with the tips located $1 \mathrm{~mm}$ above the dorsal border of the NAS using similar surgical procedures as described above. The stereotaxic coordinates used were as follows: $+3.3 \mathrm{~mm}$ from bregma, $2.7 \mathrm{~mm}$ lateral from the midline, and $-5.3 \mathrm{~mm}$ from the skull surface. The incisor bar was set $5.0 \mathrm{~mm}$ above the interaural plane, and the stereotaxic arm was angled $10^{\circ}$ from the vertical plane. The cannulae were anchored to the skull with jeweler's screws and dental cement. During the intracranial surgery, animals were implanted subcutaneously with Alzet osmotic minipumps that delivered $3 \mathrm{mg} / \mathrm{kg} / \mathrm{d}$ of heroin (Heroin Minipump group; $n=24)$. Rats in a Drug-Naive group $(n=16)$ were either implanted with minipumps containing saline or exposed to a sham operation.

Procedure. During the first week after surgery, all rats were injected with naloxone $(0.1 \mathrm{mg} / \mathrm{kg}$, s.c.) and the withdrawal symptoms of teeth chattering and wet-dog shakes were counted for $30 \mathrm{~min}$. In the second week, animals were transferred to the microdialysis setup; baseline sampling began at least $24 \mathrm{hr}$ after the insertion of the dialysis probes during the dark cycle in the absence of food. In the precipitated withdrawal condition, after several baseline samples were taken, 16 subjects from the Heroin Minipump group and 10 from the Drug-Naive group were injected with naloxone $(0.1 \mathrm{mg} / \mathrm{kg}$, s.c.), and the concentrations of DA and its metabolites dihydroxyphenylacetic acid (DOPAC) and homovanillic acid (HVA) in the NAS were determined at 20 min intervals at a flow rate of $0.6 \mu \mathrm{l} / \mathrm{min}$. In the spontaneous withdrawal condition, samples were taken for $3 \mathrm{hr}$ on the day before the minipump was removed (baseline day) and again for $3 \mathrm{hr}$ at $24 \mathrm{hr}$ after the removal of minipumps (spontaneous withdrawal day) from animals in the Heroin Minipump group $(n=8)$ and the Drug-Naive group $(n=6)$. In this condition, samples were taken at $30 \mathrm{~min}$ intervals at a flow rate of $0.2 \mu \mathrm{l} / \mathrm{min}$ (see below).

The dialysis probes consisted of a $2.0 \mathrm{~mm}$ length of semipermeable dialysis membrane ( $240 \mu \mathrm{m}$ o.d., 13,000 molecular weight cutoff; Spectrum, Houston, TX) closed at one end and attached at the other end to a $19 \mathrm{~mm}$ length of 26-gauge stainless-steel tubing. A $40-50 \mathrm{~cm}$ length of polyethylene (PE)-20 tubing connected the other end of the stainlesssteel shaft to an infusion swivel which, in turn, was connected via PE-20 tubing to a variable-speed infusion pump (Harvard Apparatus, South Natick, MA). A small-diameter fused-silica tube extended internally through the probe, with the one end resting $0.5 \mathrm{~mm}$ from the tip of the probe and the other end exiting the PE tubing 5-10 $\mathrm{cm}$ above the stainless-steel shaft. The probes were secured in place by brass collars that screwed onto the guide cannulae. The external length of PE-20 tubing was protected by a steel spring casing. The probes were designed so that the stainless-steel shaft extends $1 \mathrm{~mm}$ below the guide cannula tip and the semipermeable membrane extends $2 \mathrm{~mm}$ further after insertion. The recovery of the probes used in our laboratory is between 6 and $10 \%$. Artificial CSF (ACSF; $145 \mathrm{mM} \mathrm{Na}^{+}, 2.7 \mathrm{mM} \mathrm{K}^{+}, 1.2 \mathrm{mM} \mathrm{Ca}^{2+}, 1.0 \mathrm{~mm}$ $\mathrm{Mg}^{2+}, 150 \mathrm{mM} \mathrm{Cl}$, $0.2 \mathrm{~mm}$ Ascorbate, $2 \mathrm{mM} \mathrm{NA}_{2} \mathrm{HPO}_{4}, \mathrm{pH} 7.4$ ) was perfused through the probes overnight. Dialysate were extracted from the samples and immediately analyzed using two identical HPLC systems with electrochemical detection. The samples were loaded onto reversephase columns $\left(15 \times 0.46 \mathrm{~cm}^{2}\right.$ Spherisorb-ODS2, $5 \mu \mathrm{m}$; Chromatography Sciences, Montreal, Canada) through manual injection ports (Rheodyne $7125,20 \mu$ l loop; Cotati, CA). The reduction current for DA $(-0.27 \mathrm{~V})$ and the oxidation current for DOPAC and HVA $(0.4 \mathrm{~V})$ were measured with ESA coulometric detectors (Coulochem 5100A, with a Model 5021 Conditioning cell and a Model 5011 Analytical cell; ESA, Bedford, MA). The mobile phases $(23 \% \mathrm{MeOH}, 0.076 \mathrm{M}$ SDS, $0.1 \mathrm{~m}$ EDTA, $0.058 \mathrm{M}$ $\mathrm{NaPO}_{4}, 0.027$ M citric acid, pH 4.0) were circulated through each closed system at a flow rate of $1.0 \mathrm{ml} / \mathrm{min}$ by Waters $510 \mathrm{HPLC}$ pumps (Waters,
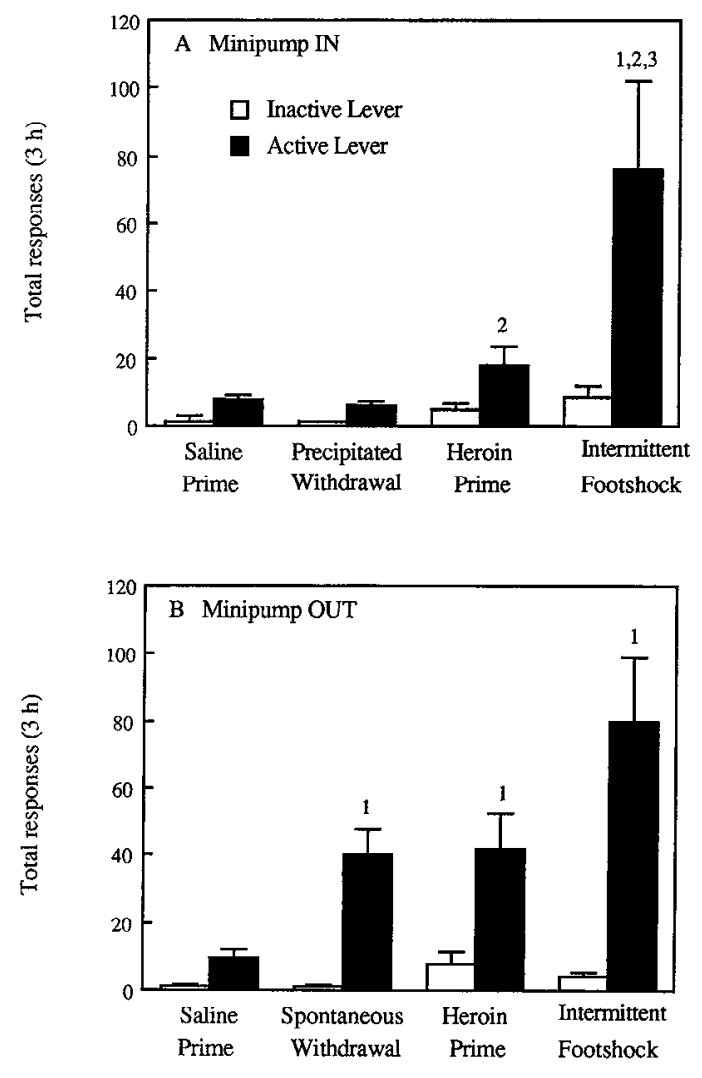

Condition

Figure 2. Reinstatement: mean \pm SEM number of presses on the previously active and inactive levers during the $3 \mathrm{hr}$ test for reinstatement. $A$, Minipump IN $(n=13)$ : Saline Prime, a noncontingent subcutaneous injection of saline; Precipitated Withdrawal, $0.1 \mathrm{mg} / \mathrm{kg}$ naloxone, s.c.; Heroin Prime, noncontingent priming injection of $0.25 \mathrm{mg} / \mathrm{kg}$ heroin, s.c.; and stress, $10 \mathrm{~min}$ exposure to Intermittent Footshock. B, Minipump OUT $(n=11)$ : Saline Prime, last lest before removal of the minipump; Spontaneous Withdrawal, $24 \mathrm{hr}$ after removal of the minipump; Heroin Prime and Intermittent Footshock as in $A$. Saline, heroin, or naloxone was injected within $10 \mathrm{~min}$ before the reinstatement test session. Intermittent footshock was administered for $10 \mathrm{~min}$ before the start of the test session. 1 , Significant difference from saline prime $(p<0.05)$. 2, Significant difference from precipitated withdrawal $(p<0.05)$. 3, Significant difference from heroin prime $(p<0.05)$.

Montreal, Canada). The peaks obtained for DA, DOPAC, and HVA were integrated by an EZchrom Chromatography Data System (Scientific Software, San Ramon, CA).

To maximize the ability to detect changes in extracellular DA during spontaneous withdrawal, the routine dialysis procedure was modified. Dialysis probes were inserted $48 \mathrm{hr}$ before testing to ensure stabilization of DA and metabolite levels over days. The flow rate was reduced and the sampling interval increased to obtain higher concentrations of DA in each sample. The minipumps were removed in the afternoon of the baseline day. At the end of the experiments, the rats were deeply anesthetized with chloral hydrate and perfused transcardially with $0.9 \%$ saline followed by $10 \%$ formalin. The brains were removed, sliced in 30 $\mu \mathrm{m}$ frozen sections, and stained with thionin for microscopic verification of the probe placement.

\section{RESULTS}

\section{Experiment 1: reinstatement}

Figures 2 and 3 show the mean number of lever presses on the active and inactive levers made during the $3 \mathrm{hr}$ tests for reinstatement after exposure to noncontingent priming injections of saline and heroin, exposure to footshock, and exposure to the opioid withdrawal conditions (naloxone-precipitated in the Minipump 


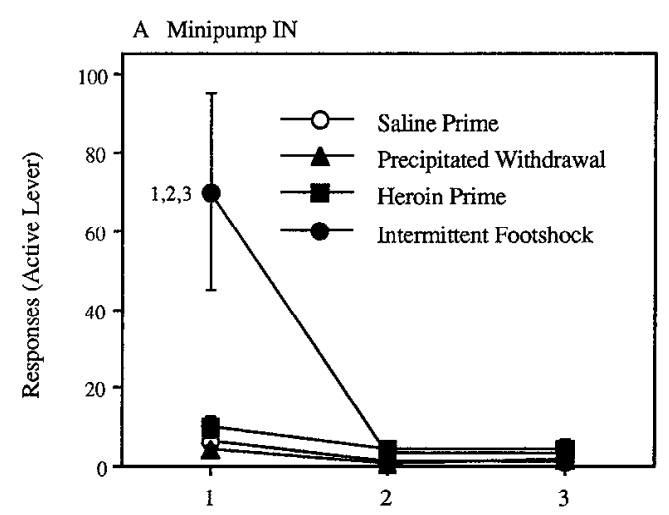

B Minipump OUT

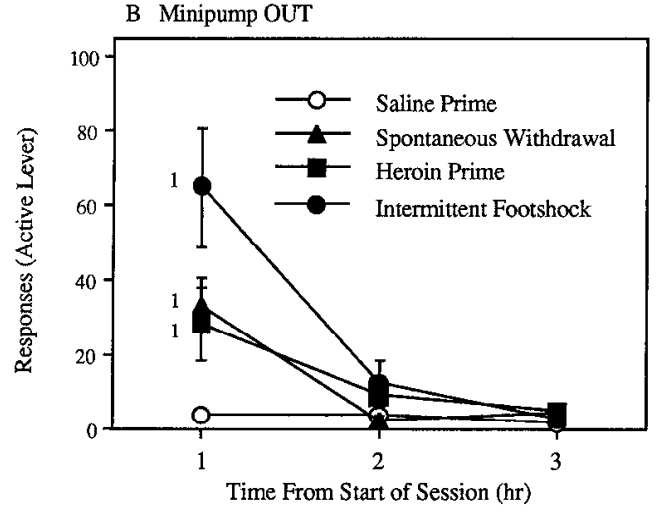

Figure 3. Reinstatement: mean \pm SEM number of presses on the previously active lever during each hour of the $3 \mathrm{hr}$ tests for reinstatement. See legend of Figure 2 for details of the experimental conditions.

IN group and spontaneous $24 \mathrm{hr}$ withdrawal in the Minipump OUT group).

In animals tested with the Minipump IN (Figs. $2 A, 3 A$ ), exposure to footshock induced significantly higher rates of pressing on the previously active lever than did saline prime, precipitated withdrawal, or the heroin priming. The number of lever presses was somewhat greater after the heroin prime than it was after either saline prime or precipitated withdrawal. A repeatedmeasures ANOVA for Test Condition and Hour revealed a significant effect of Test Condition and a significant Test Condition $\times$ Hour interaction $\left(F_{(3,36)}=6.2, p<0.01\right.$ and $F_{(6,72)}=6.4, p<$ 0.01 , respectively). The interaction reflects the fact that a miajority of responses, and the greatest differences between the conditions, occurred in the first hour.

Animals tested with the Minipump OUT (Figs. $2 B, 3 B$ ) engaged in higher levels of lever pressing on the previously active lever $24 \mathrm{hr}$ after removal of the pump (during spontaneous withdrawal), after priming injections of heroin, and after footshock than they did after the saline prime test given just before removing the pump. Repeated-measures ANOVA revealed a significant effect of Test Condition and a significant Test Condition $\times$ Hour interaction $\left(F_{(3,30)}=6.3, p<0.01\right.$ and $F_{(6,60)}=5.5, p<0.01$, respectively).

The number of lever presses in the Minipump OUT group in the test given $24 \mathrm{hr}$ after removal of the pump (spontaneous withdrawal) was significantly greater than that in the Minipump IN group after naloxone-precipitated withdrawal $\left(F_{(1,23)}=19.7, p\right.$ $<0.01)$. The number of presses after exposure to the heroin prime was higher in the Minipump OUT group than in the Minipump IN group $\left(F_{(1,23)}=4.1, p=0.05\right)$, indicating that the presence of heroin in the body attenuated the ability of acute reexposure to the drug to reinstate heroin-seeking. No significant differences between groups were found in reinstatement of heroin-seeking after either exposure to footshock stress or saline priming injections.

\section{Signs of opioid withdrawal}

One day after the removal of the minipumps, rats in the Minipump OUT group showed significant weight loss of $17.0 \pm$ $1.7 \mathrm{gm}$ compared to gain of $3.5 \pm 1.2 \mathrm{gm}$ on the day before removal and of $3.2 \pm 2.2 \mathrm{gm}$ on the second drug-free day $\left(F_{(2,22)}\right.$ $=39.0, p<0.01$ ).

Before being transferred to the microdialysis setup, both animals with heroin minipumps (Heroin Minipump group) and those in the drug-free control group (Drug-Naive group) were injected with naloxone $(0.1 \mathrm{mg} / \mathrm{kg})$, and the incidence of withdrawal signs was recorded for $30 \mathrm{~min}$. Rats implanted with the heroin minipumps $(n=24)$ showed a much greater incidence of withdrawal symptoms than the drug-naive control rats $(n=16)$ (teeth chattering: $7.0 \pm 1.0$ vs $0.06 \pm 0.06$; wet-dog shakes: $25.5 \pm 3.4$ vs $6.0 \pm 2.0 ; F_{(1,38)}=31.5, p<0.01$, and $F_{(1,38)}=19.0, p<0.01$, respectively).

\section{Experiment 2: microdialysis}

Only those animals with cannulae located within the region 3-4 $\mathrm{mm}$ anterior from bregma (Pellegrino et al., 1979) were included in the analyses. In the test for precipitated withdrawal, the mean baseline levels of DA were $2.2 \pm 0.2$ and $2.0 \pm 0.2 \mathrm{pg} / 10 \mu \mathrm{l}$ for the Drug-Naive group and the Heroin Minipump group, respectively. Naloxone-precipitated withdrawal was accompanied by modest decreases over time from baseline in DA, DOPAC, and HVA concentrations in the NAS (Fig. 4). The statistical analyses were conducted on actual concentrations of DA, DOPAC, and HVA; these included a baseline value (mean of last 3 samples) and the nine postinjection samples over $3 \mathrm{hr}$. The ANOVA revealed significant or marginally significant Group $\times$ Time interactions for DA, DOPAC, and HVA $\left(F_{(9,162)}=1.81, p=0.07, F_{(9,162)}=\right.$ $3.8, p<0.01$, and $F_{(9,162)}=4.3, p<0.01$, respectively), reflecting the fact that levels were reduced after naloxone injection in the Heroin Minipump group and remained stable in the Drug-Naive group. It should be noted that the Group $\times$ Time interaction for the analysis of DA levels was only marginally significant because of individual variations and the fact that DA tended to return to baseline levels toward the end of the session (Fig. 4A). A second analysis was carried out using the data for the first $2 \mathrm{hr}$ after the naloxone injection. This analysis revealed a significant Group $\times$ Time interaction $\left(F_{(6,108)}=2.35, p<0.05\right)$. In addition, a withingroup analysis for the Heroin Minipump group using data for baseline and the first $2 \mathrm{hr}$ after naloxone injections revealed a significant Time effect $\left(F_{(6,60)}=2.73, p<0.05\right)$. No significant differences were observed in the within-group analyses in the Drug-Naive group.

The levels of DA, DOPAC, and HVA during withdrawal precipitated by injection of naloxone to animals in the Heroin Minipump group are presented as percent change from baseline levels in Figure 4; significant differences (covarying for baseline levels) between the Drug-Naive group and the Heroin Minipump group at individual time points are indicated. Significant differences between baseline level and individual time points after the injection of naloxone within each group are also indicated.

The effect of the spontaneous withdrawal condition $(24 \mathrm{hr}$ after 

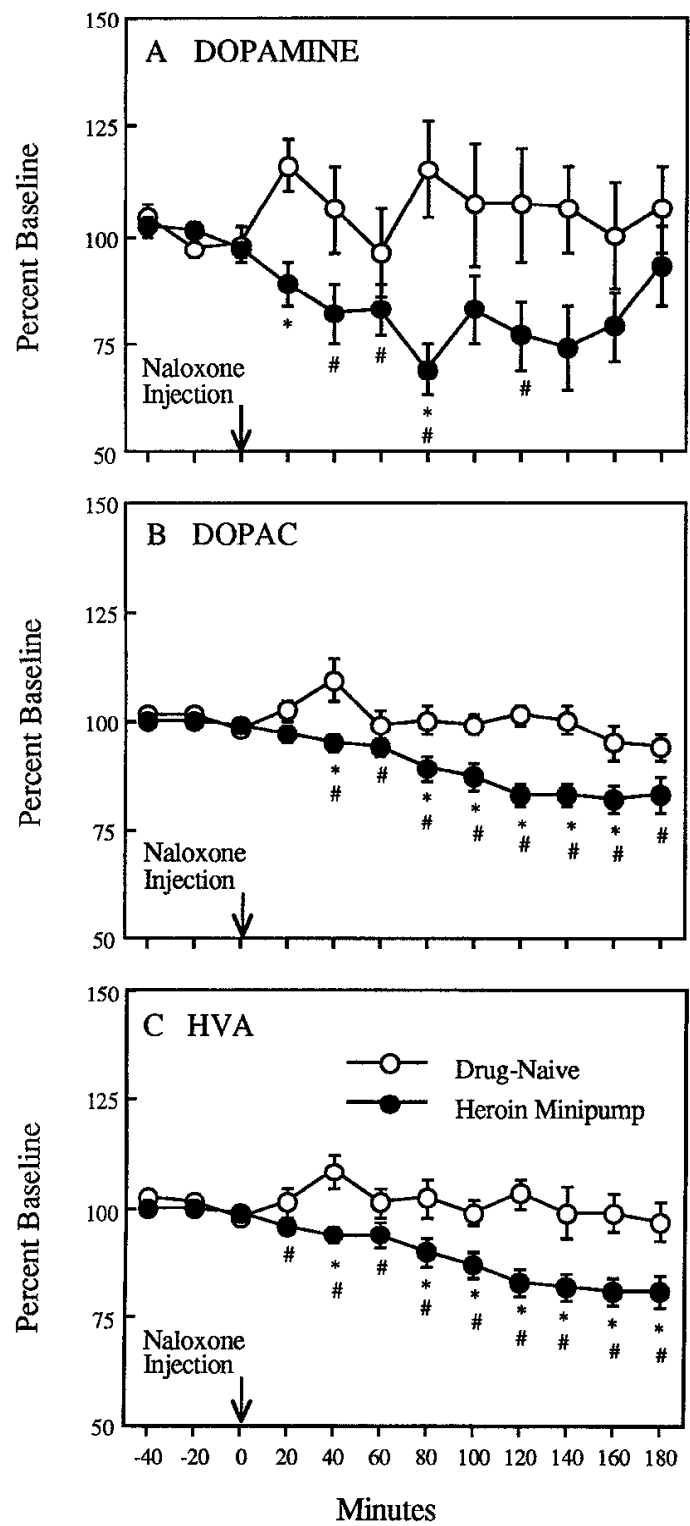

Figure 4. Microdialysis. Precipitated withdrawal: mean \pm SEM percent change from baseline levels of $(A) D O P A M I N E,(B) D O P A C$, and $(C)$ $H V A$ in the NAS in the Drug-Naive group $(O ; n=9)$ and the Heroin Minipump group $(\bullet ; n=11)$ after injection of $0.1 \mathrm{mg} / \mathrm{kg}$ naloxone, s.c. "Significant differences between groups at individual time points $(p<$ $0.05)$. ${ }^{\#}$ Significant differences between the mean baseline value and individual time points after the injection of naloxone for the Heroin Minipump group $(p<0.05)$.

the removal of the heroin minipump) on DA, DOPAC, and HVA levels is presented in Figure 5. There were no statistically significant differences in the levels of DA, DOPAC, or HVA between the Heroin Minipump group and the Drug-Naive group or between days (baseline day vs the subsequent day, $24 \mathrm{hr}$ after removal of the minipump) within each group.

\section{DISCUSSION}

Several findings of both theoretical and practical interest emerge from these experiments. First, brief exposure to footshock stress reinstates drug-seeking in the presence of heroin delivered continuously by minipump, as well as in the drug-free state (Shaham and Stewart, 1995b). Priming injections of heroin, however, are much less effective in reinstating heroin-seeking in the presence of the minipump. We have found recently that, unlike the effect of priming injections of heroin, the effect of footshock on reinstatement is not dependent on activation of opioid receptors; in heroin-trained rats, the opioid antagonist naltrexone $(1-10 \mathrm{mg} /$ $\mathrm{kg}$ ) blocked heroin-induced reinstatement (see also Stewart, 1984), but had no effect on footshock-induced reinstatement (Shaham and Stewart, 1995a). The fact that footshock stress reinstated drug-sceking in heroin-maintained animals confirms clinical impressions that stressors can provoke relapse in individuals chronically treated with the opioid agonist methadone (Whitehead, 1974).

The second important finding is that naloxone-precipitated withdrawal, manifested by overt physical symptoms of withdrawal and by modest reductions in basal levels of DA and its metabolites in the NAS, did not reinstate heroin-seeking. This result found here in animals maintained on the heroin minipump replicates our previous finding in heroin-free animals after long-term extinction (Shaham and Stewart, 1995b). The finding is particularly significant because in the present study animals were given one self-administration session daily in an effort to ensure that they would experience some symptoms of withdrawal just before heroin availability each day and, thereby, learn that drug-taking can relieve these symptoms. Despite these conditions, however, the naloxone-precipitated state of withdrawal failed to induce relapse. It should be noted that it is likely that the rats experienced withdrawal under the training conditions used. We recently observed in animals allowed to self-administer heroin for one session per day a mild withdrawal state in the morning before the selfadministration session for heroin [mean \pm SEM occurrence of wet-dog shakes $(8.4 \pm 1.3)$ and teeth chattering $(4.2 \pm 1.0)$ in 30 IniII; $n=15$ ].

Third, in contrast to the behavior of animals during naloxoneprecipitated withdrawal, reinstatement of heroin-seeking was observed when rats were given access to the active lever $24 \mathrm{hr}$ after removal of the heroin minipump. Similarly, relapse to heroin use in humans is commonly found after the termination of the maintenance therapy (Jaffe, 1985). This may be accounted for in part by the fact that while on maintenance therapy, individuals do not have the opportunity to dissociate the experience of withdrawal from drug-taking. Also, in the present experiment animals tested in the absence of the minipump, although they had experienced extinction conditions in the presence of heroin in the body, had never undergone extinction in the drug-free state. The conditions that existed after the removal of the minipump would have been very similar to those that occurred each day during daily heroin self-administration. Thus, the lack of extinction and the reestablishment of the state of spontaneous withdrawal made it highly probable that the lever and other drug-related cues remained salient stimuli for these animals. What we do not know from this experiment is whether animals given repeated experience with extinction in the drug-free state before implantation of the minipumps would be as susceptible to reinstatement of drugseeking $24 \mathrm{hr}$ after minipump removal. We did confirm that $24 \mathrm{hr}$ after removal of the minipump, animals had lost a significant amount of body weight, a major sign of opioid withdrawal; we did not observe, however, any change in basal levels of DA in the NAS at this time. Thus, in these experiments no correlation between reduced basal levels of DA in NAS and reinstatement of heroinseeking was found. The spontaneous withdrawal condition, evoked by removal of the minipump, reinstated heroin-seeking in the absence of changes in basal DA and its metabolite levels in the NAS, whereas naloxone-precipitated withdrawal modestly de- 
A Day before pump removal
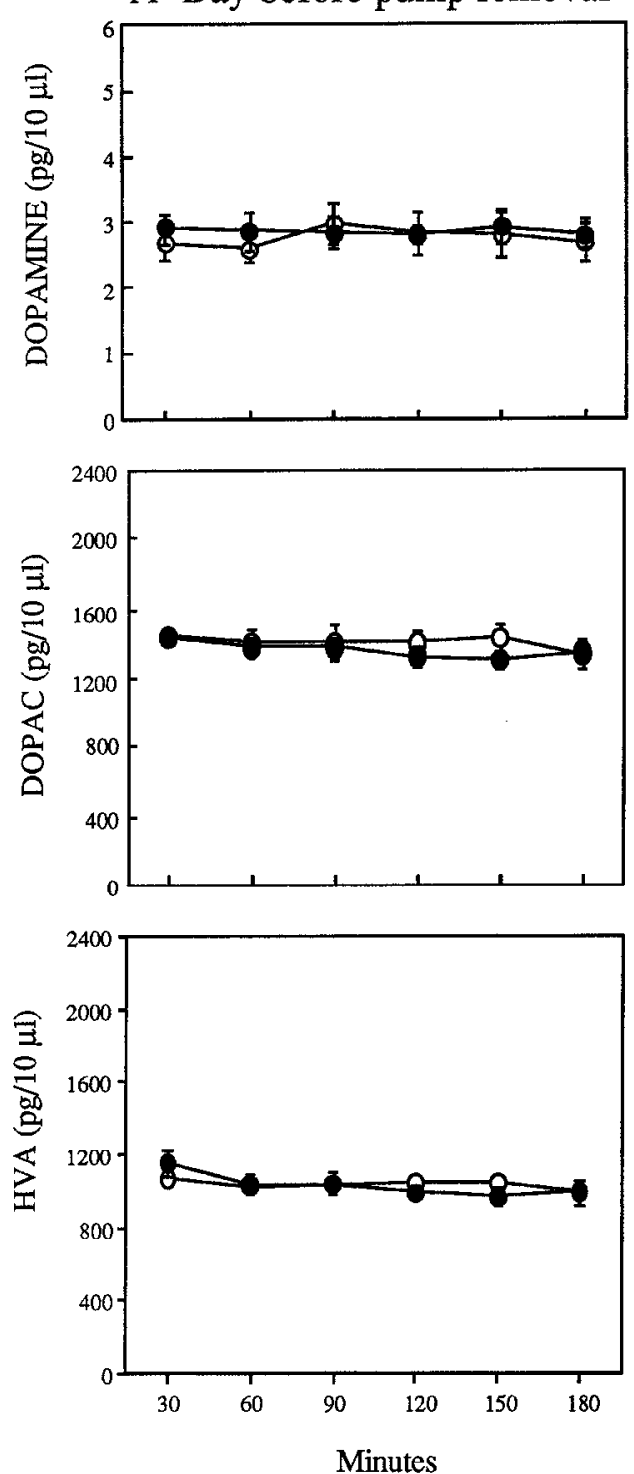

B $24 \mathrm{~h}$ after pump removal
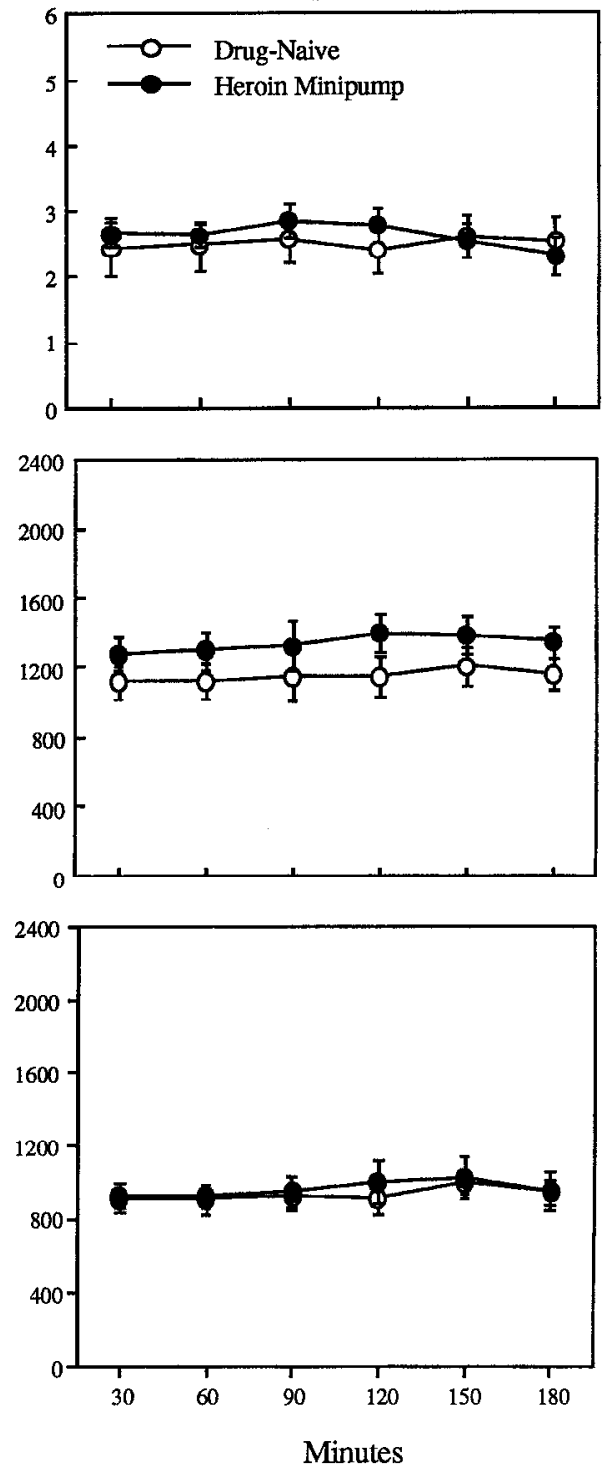

Figure 5. Microdialysis. Spontaneous withdrawal: mean \pm SEM levels of DOPAMINE, $D O P A C$, and $H V A$ in the NAS $(A)$ on baseline day before removal of the heroin minipumps, and $(B) 24 \mathrm{hr}$ after the removal of the heroin minipumps in the Drug-Naive group $(O ; n=6)$ and the Heroin Minipump group $(0 ; n=6)$. Data are from six consecutive samples taken over a $3 \mathrm{hr}$ period. creased basal levcls of DA and its metabolites but did not rcinstate heroin-seeking.

Our finding that naloxone-precipitated withdrawal is associated with reduced basal levels of DA in the NAS is similar to that of others (Pothos et al., 1991; Rossetti et al., 1992). It should be noted, however, that a more modest reduction in DA levels was observed in precipitated withdrawal condition in the present study than in previous studies. Also, unlike others (Acquas et al., 1991; Crippens and Robinson, 1994; Spanagel et al., 1994) we did not observe under the conditions of this experiment reduced basal levels of DA in spontaneous withdrawal from opioids. These discrepancies are probably attributable to the lower doses of the opioid agonist and antagonist we used $(3 \mathrm{mg} / \mathrm{kg} / \mathrm{d}$ of heroin and $0.1 \mathrm{mg} / \mathrm{kg}$ naloxone) compared with those used in these other studies (up to $240-280 \mathrm{mg} / \mathrm{kg} / \mathrm{d}$ of morphine and much higher doses of naloxone or naltrexone). It should be noted, however, that a similar decrease in metabolites levels observed in the present studies was found in other studies that examined the precipitated withdrawal condition (Z. Rossetti, personal communication). Thus, it appears that the precipitated withdrawal con- dition in the present study caused a modest reduction in the functioning of DA in the NAS.

In summary, the present results do not support the idea that decreased DA availability in the NAS after cessation of exposure to drugs of abuse is associated with reinstatement of drug-seeking. The results are, however, in agreement with evidence from experiments showing that decreased DA function is associated with a reduction in responding for natural reinforcers, stimuli previously associated with the unconditioned reinforcers (conditioned reinforcers), and for rewarding electrical brain stimulation. Previous studies indicate that DA receptor antagonists increase the threshold for electrical brain stimulation (Wise and Rompré, 1989), decrease the consumption of palatable food (Hsiao and Smith, 1995), attenuate reinstatement of heroin-seeking by heroin priming injections (Shaham and Stewart, 1995a), and decrease responding for conditioned reinforcers (Beninger and Ranaldi, 1994). Similarly, the state of withdrawal from drugs of abuse increases threshold for brain stimulation and decreases the consumption of palatable food (Kokkinidis and McCarter, 1990; Lieblich et al., 1991; Markou and Koob, 1991; Schulteis et al., 
1995). In contrast, increased mesolimbic DA utilization facilitates appetitive behavior (Wise and Rompré, 1989), potentiates responses for conditioned reinforcers during extinction (Robbins, 1975), and reinstates heroin-seeking (Stewart, 1984; Stewart and Vezina, 1988). The evidence presented here from spontaneous withdrawal from a moderate dose of heroin suggests that at least normal basal levels of intra-NAS DA are required for conditioned stimuli previously associated with drug-taking (e.g., extension of the lever) to induce reinstatement of drug-seeking.

\section{REFERENCES}

Acquas E, Carboni E, Di Chiara G (1991) Profound depression of mesolimbic dopamine release after morphine withdrawal in dependent rats. Eur J Pharmacol 193:133-134.

Beninger R, Ranaldi R (1994) Dopaminergic agents with different mechanisms of action differentially affect responding for conditioned reward. In: Strategies for studying brain disorders, Vol 1, Depressive, anxiety and drug abuse disorders (Palomo T, Trevor A, eds), pp 411-428. Madrid: Farrand.

Blasig J, Herz A, Reinhold K, Zieglgansberger S (1973) Development of physical dependence on morphine in respect to time and dosage and quantification of the precipitated withdrawal syndrome in rats. Psychopharmacologia 33:19-38.

Childress A, Mclellan T, O'Brien C (1986) Role of conditioning factors in the development of drug dependence. Psychiatric Clin North Am 9:413-425.

Crippens D, Robinson TE (1994) Withdrawal from morphine and amphetamine different effects on dopamine in the ventral-medial striatum studied with microdialysis. Brain Res 650:56-62.

Devine DP, Wise RA (1994) Self-administration of morphine, DAMGO, and DPDPE into the ventral tegmental area of rats. J Neurosci 14:1978-1984.

Devine DP, Leone P, Pocock D, Wise RA (1993) Differential involvement of ventral tegmental mu, delta, and kappa opioid receptors in the modulation of basal mesolimbic dopamine release: in vivo microdialysis studies. J Pharmacol Exp Ther 266:1236-1246.

Di Chiara G, Imperato A (1988) Drugs abused by humans preferentially increase synaptic dopamine transmission concentration in the mesolimbic system of freely moving rats. Proc Natl Acad Sci USA 85:5274-5278.

Harris GC, Aston-Jones G (1994) Involvement of D2 dopamine receptors in the nucleus accumbens in the opiate withdrawal syndrome. Nature 371:155-157.

Himmelsbach C (1943) With reference to physical dependence. Fed Proc 2:201-203.

Hsiao O, Smith G (1995) Raclopride reduces sucrose preference in rats. Pharmacol Riochem Behav 50:121-125.

Jaffe JH (1985) Drug dependence. In: Comprehensive textbook of psychiatry (Kaplan HI, Sadock BJ, eds), pp 987-1033. Baltimore: Williams \& Wilkins.

Kokkinidis L, McCarter B (1990) Postcocaine depression and sensitization of brain-stimulation reward: analysis of reinforcement and performance effects. Pharmacol Biochem Behav 36:463-471.

Koob G, Maldonado R, Stinus L (1992) Neural substrate of opiate withdrawal. Trends Neurosci 15:186-191.

Lieblich I, Yirmiya R, Liebeskind J (1991) Intake of and preference for sweet solutions are attenuated in morphine-withdrawn rats. Behav Neurosci 105:965-970.

Markou A, Koob G (1991) Postcocaine anhedonia: an animal model of cocaine withdrawal. Neuropsychopharmacologia 4:17-26.

Miller D, Dougherty J, Wikler A (1979) Interoceptive conditioning through repeated suppression of morphine abstinence. II. Relapsetesting. Pav J Biol Sci 14:170-176.

Nichols J, Headlee C, Coppock H (1956) Drug addiction. I. Addition by escape training. J Am Pharmacol Assoc 45:788-791.

O'Brien C, Ehrman RN, Ternes JW (1986) Classical conditioning in human opioid dependence. In: Behavioral analysis of drug dependence (Goldberg SR, Stolerman IP, eds), pp 329-356. New York: Academic.

O'Brien C, Childress A, Mclellan T, Ehrman R (1992) Classical conditioning in drug dependent humans. Ann NY Acad Sci 654:400-415.
Pellegrino LJ, Pellegrino AS, Cushman AJ (1979) A stereotaxic atlas of the rat brain. New York: Plenum.

Pothos E, Rada P, Mark G, Hoebel B (1991) Dopamine microdialysis in the nucleus accumbens during acute and chronic morphine, naloxoneprecipitated withdrawal and clonidine treatment. Brain Res $566: 348-350$.

Robbins $T$ (1975) The potentiation of conditioned reinforcement by psychomotor stimulant drugs: a test of Hill's hypothesis. Psychopharmacolugia 45:103-114.

Rossetti ZL, Melis F, Carboni S, Gessa GL (1992) Dramatic depletion of mesolimbic extracellular dopamine after withdrawal from morphine, alcohol, and cocaine: a common neurochemcial substrate for drug dependence. Ann NY Acad Sci 654:513-516.

Schulteis G, Markou A, Cole M, Koob G (1995) Decreased brain reward produced by ethanol withdrawal. Proc Natl Acad Sci USA 92:5880-5884.

Shaham Y, Stewart J (1995a) Characterization of stress- and heroinprimed relapse to heroin-seeking behavior in rats. Soc Neurosci Abstr 21:725.

Shaham Y, Stewart J (1995b) Stress reinstates heroin-seeking in drugfree animals: an effect mimicking heroin, not withdrawal. Psychopharmacologia 119:334-341

Shippenberg T, Herz A, Spanagel R, Bals-Kubik R, Stein C (1992) Conditioning of opioid reinforcement: neuroanatomical and neurochemical substrates. AnII NY Acad Sci 654:347-356.

Siegel S (1977) Learning and psychopharmacology. In: Psychopharmacology in the practice of medicine (Jarvik ME, ed), pp 59-70. New York: Appleton-Century-Crofts.

Sobrero P, Bouton M (1989) Effects of stimuli present during oral morphine administration on withdrawal and subsequent consumption. Psychobiology 17:179-190.

Solomon R, Corbit J (1974) An opponent process theory of motivation. I. Temporal dynamics of affect. Psychol Rev 81:119-145.

Spanagel R, Almeida FX, Bartl C, Shippenberg TS (1994) Endogenous $\kappa$-opioid systems in opiate withdrawal: role in aversion and accompanying changes in mesolimbic dopamine release. Psychopharmacologia 115:121-127.

Stewart. I (1984) Reinstatement of heroin and cocaine selfadministration behavior in the rat by intracerebral application of morphine in the ventral tegmental area. Pharmacol Biochem Behav 20:917-923.

Stewart J, Eikelboom R (1987) Conditioned drug effects. In: Handbook of psychopharmacology (Iversen LL, Iversen SD, Snyder SH, eds), pp 1-57. New York: Plenum.

Stewart J, Vezina P (1988) A comparison of the effects of intraaccumbens injections of amphetamine and morphine on reinstatement of heroin intravenous self-administration behavior. Brain Res 457:287-294.

Stewart J, de Wit H, Eikelboom R (1984) Role of unconditioned and conditioned drug effects in the self-administration of opiates and stimulants. Psychol Rev 91:251-268.

Thompson T, Ostlund W (1965) Susceptibility to readdiction as a function of the addiction and withdrawal environments. J Comp Psychol 60: $388-392$

Whitehead CC (1974) Methadone pseudowithdrawal syndrome: paradigm for a psychopharmacological model of opiate addiction. Psychosom Med 36:189-198.

Wikler A (1973) Dynamics of drug dependence, implication of a conditioning theory for research and treatment. Arch Gen Psychiatry 28:611-616.

Wikler A, Pescor FT (1967) Classical conditioning of a morphine abstinence phenomenon, reinforcement of opioid-drinking behavior and "relapse" in morphine-addicted rats. Psychopharmacologia 20:255-284.

Wikler A, Pescor F, Miller D, Morrel H (1971) Persistent potency of a secondary (conditioned) reinforcer following willulrawal of morphine from physically dependent rats. Psychopharmacologia 20:103-117.

Wise RA, Rompré P-P (1989) Brain dopamine and reward. Annu Rev Psychol 40:191-225. 